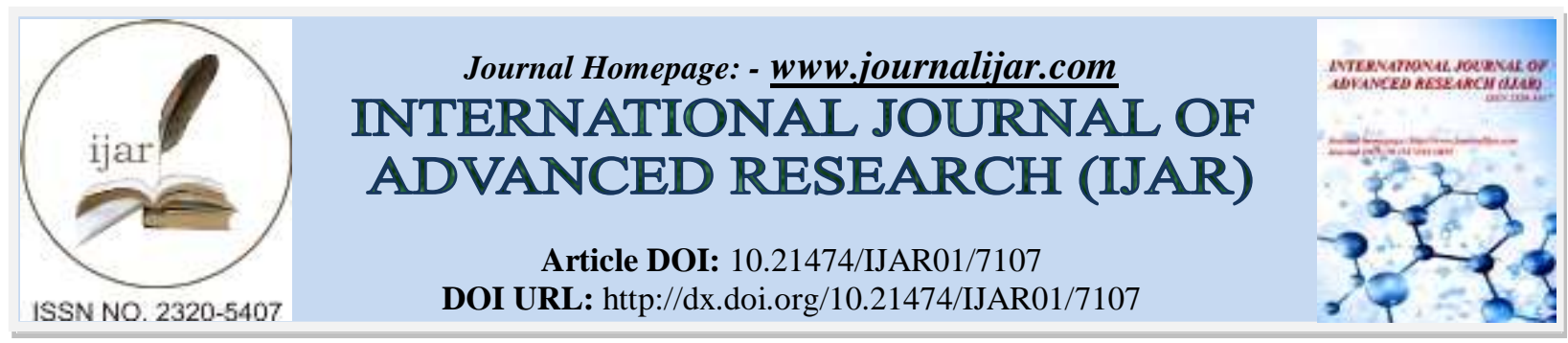

RESEARCH ARTICLE

\title{
UTILITY ESTIMATES OF A NEEDS-BASED MODEL INSTRUMENT IN COLLEGE STUDENTS HAVING ACADEMIC ISSUES: INITIAL REPORTS OF VALIDITY AND ITS IMPLICATIONS TO PSYCHOEDUCATIONAL ASSESSMENT AND INTERVENTION.
}

Ryan Dale B. Elnar.

University of Mindanao, Philippines.

\section{Manuscript Info}

Manuscript History

Received: 15 March 2018

Final Accepted: 17 April 2018

Published: May 2018

Keywords:-

needs-based model, exploratory factor analysis, confirmatory factor analysis, validity, psycho-educational assessment.

\begin{abstract}
This paper reports the utility of a needs-based model psychological instrument in students beset with personal and academic issues using content analysis, and further discusses its initial validity measures using exploratory and confirmatory factor analyses (EFA, CFA) in order to explain its psychometric soundness as needs model comprising these domains: Personal autonomy, Affective integration, Spiritual enrichment, Self-management, Career exploration, and Family attachment (PASSCF). After series of data analyses, the one-factor-sixdimensional model shows high consistency and validity wherein it signifies strong diagnostic ability to measure students' personal and academic problems affecting their college life in conjunction with other measures. Finally, implications for psycho-educational assessment and intervention are discussed based on research findings.
\end{abstract}

Copy Right, IJAR, 2018,. All rights reserved.

\section{Introduction:-}

Oftentimes, teachers refer students to guidance counselors to resolve academic concerns. However, the decline for scholastic achievements may indicate deeper problems. Beyond parental involvement, there might be students' needs that are unmet, and should be taken into account through a resourceful identification on each of them, especially in school. As observed by Feuerborn and Chinn (2012), experienced teachers perceived that students' behavioral issues can be solved by building a positive relationship from the beginning of the school year because students tend to work with teachers they respect and who they feel respect them. In the same research, four domains of student concerns that demonstrate two important implications for positive behavior support; one is poor interactions with peers including social withdrawal, and the other is poor relationships with adults including lack of trust and noncompliance.

Collecting data about students' needs can be a critical component of instruction and academic or behavioral interventions. This infers the theory of students' needs of Glasser (1999) as a useful model and relatively, a sound basis for doing a functional assessment for students' behaviors which gives a glaring signal the value of assessment to be a critical component of instruction and academic-behavioral intervention plans (Burns et al., 2006). Hence, this need-fulfillment program manifested the necessity to diagnose students' needs since proper assessment of their needs such as the use of valid and reliable tools can propel better student outcomes which include better influence to scholastic achievement (Tinto, 1987, 2005; Astin, 1997, 1984). Related studies also shared similar ideas wherein proper diagnosis of students' needs could equally influence students' behaviors related to personality and its relationship to career outcomes (Elnar, 2014) while some needs particularly the need for spirituality are also found important in spiritual global domain (Elnar, Almacin, Catacutan \& Mondigo, 2018). 
In a theoretical viewpoint, Reeve, Deci and Ryan (1999) provided one of the most ground-breaking need constructs applied in the school setting. According to their self-determination perspective, psychological needs, which are validated in schools in terms of physical exercise (Vlapoulus \& Michailidou, 2006), school counseling (Hyun, Quinn, Madon, \& Lustig, 2006), and clinical practice using psychotherapy (Kormas, Karamali \& Anagnostopoulos, 2014), are part of the organismic necessities for health which contain different subsets of needs essential for psychological growth, integrity and wellness (Deci \& Ryan, 2012).

Moreover, in an attempt to improve the utility of Glasser's early research works, a survey was conducted to validate the Choice Theory Basic Needs Scale (LaFond, 2000). The need instrument showed high content validity; however confirmatory factor analysis revealed low-item scale correlations (construct validity). In the same vein, the 20-item Basic Needs Survey (BNS) was validated by Harvey and Retter (1995) and it was found to have high reliability (.66 to .79), but a minimal difference between the subscale scores for each of the needs was also found. Again the BNS study describes the overall need structure, however it does not provide the specific measure on how well the school is meeting the students' needs.

Literature analysis, as well, indicates that utility of the needs scales is consumed mostly by, if not all, the clinical or non-academic population. Besides, despite the importance of the needs assessment in the academe, a dearth literature cited the development and administration of students needs in the tertiary schools. For instance, Picklesimer and Miller (1998) made the instrument for measuring life-skill achievement of college students. Meager validation research about needs in schools is also seen in 2010 wherein literature reveal that only the works of Giovazolias, Leontopoulou and Triliva (2010) explored the scale for Greek University Students' Counseling Needs and Attitudes.

According to Marshall (2013), there had been methodological and ethical controversies related to the use of standardized tests within non-western contexts. It was further argued that culturally relevant psychological tests should be developed in our own local context and its utility in testing psychological construct. This implies that the need to develop and utilize appropriate measurement to capture the holistic nature of college needs using Filipino samples is imperative (Armani, Sta. Maria \& Jeswani, 2011). Hence, based on the above discourses, developing and validating culture-sensitive need scale for Filipinos undoubtedly propelled important theoretical and practical implications to clinicians, educators, administrators and future researchers in the hope of developing a more relevant and context-specific psycho-educational assessment and intervention plans (Elnar, 2015, 2018).

\section{Methodology:-}

This paper validates the usefulness of 32-item instrument developed to measure student's needs particularly those who are having academic issues. Anchored on Creswell's (2009) mixed-method of analysis, this inquiry is carried out using a semi-qualitative and quantitative approach of research, an approach which is also suited for determining validity as opined by Creswell and Miller (2000). The need instrument being used in the study is the Scale of Filipino Students Need (SFSN-C) developed by Elnar (2015) which constructively contain a one-factor-sixdimensional instrument normed for college students. Elnar's SFSN-C underwent reliability and validity protocols and was developed as part of his dissertation requirement in one of the universities in Southern Philippines in 2015.

\section{Instrument Development Process:-}

First, Elnar (2015) qualitatively investigated (eg. FGD) the presence of the identified need factors using student samples. Second, the test developer quantified the test items' construct validity for every dimension through exploratory factor analysis (EFA) and he later used the indices results of the conducted confirmatory factor analysis (CFA) for theory testing (Elnar, 2018). The reliability of the initial scale was also established using internal consistency analysis and test-retest (Cronbach Alpha). Figure 1 shows the test development process in the preliminary validation study. 


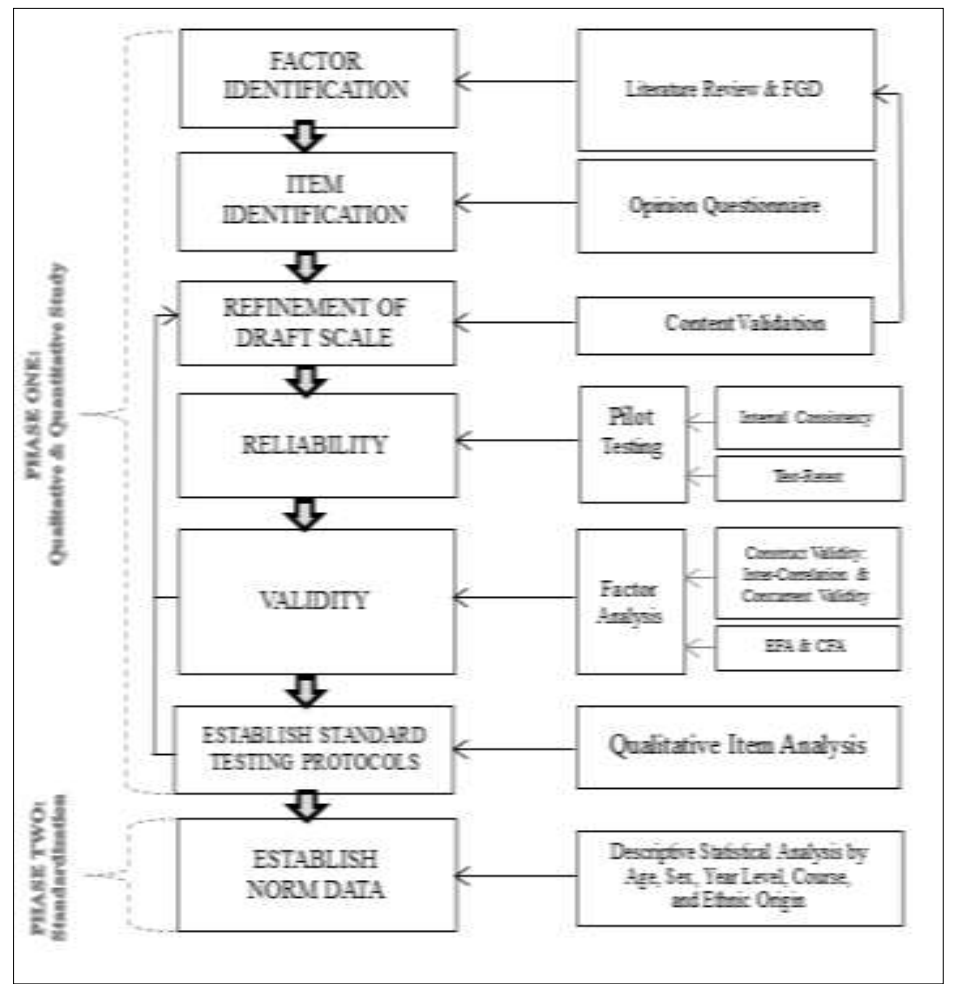

Figure 1:- Test development process used in the initial validity study

Third and lastly, this research is considered as an "expansion pack" of the validation study conducted by Elnar in 2015. In particular, it focuses on the following research questions: (1) what is the psychometric efficacy of the SFSN-C when utilized by students who have academic and non-academic concerns? (2) In effect, does SFSN-C show its predictive validity to determine students' personal and academic problems in conjunction with other measures?

To complement the results of the validation studies, a qualitative approach to inquiry in view of establishing the standard psychometric quality of the instrument was also conducted. Both thematic and content analyses were adapted to analyze qualitative data.

Data were elicited from another set of sample culled from those who already took the experimental items of the instrument. The participants were invited to a Focus Group Discussion (FGD) through the Psychology Department's Year Level Adviser wherein most of the participants were psychology majors $(n=12)$. This method was used by the researcher because it suits the purpose of improving the practicality of the instrument to be utilized by the college students. Using the ethical protocols of data collection, the participants have signed the Participants' Consent Form before they were allowed to participate in the FGD. Prior to the conduct of the FGD, it was ensured that all FGD participants were able to take the final 32-item of the SFSN-C. Students were also oriented about the purpose of the psychological testing and they were able to receive the token from the researcher after the FGD was conducted. Thus, rights and privileges of the FGD participants were clearly articulated before the FGD was conducted.

The researcher initially asked the participants' perceptions about their observations between the old version (117 items) and recent version (32 items) of the SFSN-C. Most of them agreed that the recent version containing 32 items is more practical and reliable items to measure their needs. They observed that recent version's format and clarity of the items are coherent with the way they want the test should be. In fact, most of them revealed that even during the test-taking alone they can already evaluate and reflect on what possible needs they want to satisfy in school and also at home. 
To test the usefulness of the standardized instrument, the researcher invited some of the students who availed the counseling and psychological assessment services of the Guidance and Testing Center (GTC). Through the aid of the guidance counselor, there were 43 students under all college programs who took part in the test utility procedures. They were able to take both the SFSN-C and the Mooney Problem Checklist (MPC) (Mooney \& Gordon, 1950) for about one-hour test administration at the GTC. Informed consent was also sought from the test takers before they were able to take the tests.

\section{Results and Discussion:-}

To improve the clarity of the presented table and figure, the researcher provides the results and discussions of the initial study showing its reliability and validity studies. Samples' demographics are also explained for further reference.

\section{Results of the Initial Validity Studies:-}

During the initial validity study, the subscales' overall internal consistency of the try-out sample is excellent, ranging from .73-.90 Cronbach Alpha. It shows that all need items' reliability has shown high stability and internal consistency, thus the instrument is highly reliable in measuring the college needs. This is evident on the overall Cronbach Alpha of .94 which shows an excellent descriptive rating (Furr \& Bacharach, 2014). This result was in accordance with the ideas of Cohen et al. (2013) that the reliability of a test should be stable over time and should be internally consistent. Similarly, the current result on reliability somehow coheres with the findings of Burns et al. (2006) on the psychometric measure of five basic needs.

\section{Exploratory Factor Analysis:-}

Data screening was conducted prior to exploratory factor analysis wherein Kaiser-Meyer-Olkin $(\mathrm{KMO}=0.892)$ and Bartlett's test of sphericity ensured sampling adequacy of the EFA sample $(n=300)$. To examine factorial correlation, an oblimin rotation was chosen for it is a simple structure of the item loadings (Kline, 2010). The result shows that the sample entered for data processing was adequate which surpassed the cutoff threshold of.05 as opined by Kaiser \& Michael (1975).

To determine the number of factors that SFSN-C contains, Scree plot illustrates a multi-dimensional instrument. A multidimensional instrument is higher-order factors containing several attributes and yet homogenous to measure a specific attribute (Furr and Bacharach, 2014). Taken as one, all attributes can measure only one construct which is this case the college needs.

Initial factor rotation yielded to 13 factors, however, some items were eliminated due to item isolation issue and to ensure how robust each factor is and it must be greater than 0.60 comprising at least three items (Rozeboom, 1992 as cited in Fabrigar et al. 1999). Final factor rotation reduced it to a 6-factor composed of 28 items was found, as shown in Table1. The researcher used the set criteria of Furr (2011) citing that any item having the factor loadings of .30 or .40 indicate reasonable value, while a factor loading value of .70 or higher is considered very strong.

The Six Need Model (PASSCF) :-

Literature analysis reveals that F6 is composed of Personal autonomy items which are widely articulated in Selfdetermination concept (Deci \& Ryan, 1995). Meanwhile, Affective Integrative is F5 comprising 4 items of emotionrelated items. F5 relates to the study of Mitsopoulou et al. (2012) citing the value of emotion regulation as a coping strategy in adult samples. F4, which is consist of spiritual-related items called as Spiritual enrichment, is in accord with the research of Piedmont (2001). In his study, he considered spirituality as having a relationship to the fivefactor model of personality in students in which he further denotes "spiritual constructs can be most efficacious in conjunction with multidimensional assessment battery that included other personality domains." F3 is a factor that comprised of 4 items which can be named as Self-management since it relates to an awareness and strategies for handling personal situations.

Table 1:- Factor Loadings of the SFSN-C

\begin{tabular}{|c|c|c|c|c|c|c|c|}
\hline \multirow{2}{*}{$\begin{array}{l}\text { Item } \\
\text { Code }\end{array}$} & \multirow[t]{2}{*}{ Need Statement } & \multicolumn{6}{|c|}{ Factor } \\
\hline & & F1 & F2 & $\mathbf{F 3}$ & F4 & F5 & F6 \\
\hline FA_86 & experience my family's love and care. & .799 & & & & & \\
\hline FA_46 & $\begin{array}{l}\text { have the support of my family in what is important } \\
\text { to me. }\end{array}$ & .785 & & & & & \\
\hline
\end{tabular}




\begin{tabular}{|c|c|c|c|c|c|c|c|}
\hline FA_41 & have a good dinner with my family. & .707 & & & & & \\
\hline FA_56 & make my family proud for having good grades. & .701 & & & & & \\
\hline FA_83 & be able to get along well with my family members. & .694 & & & & & \\
\hline FA_50 & able to resolve conflict in my family. & .664 & & & & & \\
\hline CE_110 & $\begin{array}{l}\text { explore which careers could be best fit to my } \\
\text { interests and abilities. }\end{array}$ & & .843 & & & & \\
\hline CE_112 & $\begin{array}{l}\text { improve on my ability to concentrate when } \\
\text { studying. }\end{array}$ & & .759 & & & & \\
\hline CE_103 & $\begin{array}{l}\text { be clear about the kind of job I would be doing in } \\
\text { the future. }\end{array}$ & & .710 & & & & \\
\hline CE_78 & $\begin{array}{l}\text { have an on-the-job experience for the work that I } \\
\text { want. }\end{array}$ & & .650 & & & & \\
\hline CE_94 & $\begin{array}{l}\text { have trainings on how to apply what I learned in } \\
\text { the classroom. }\end{array}$ & & 621 & & & & \\
\hline CE_16 & $\begin{array}{l}\text { do an experiment to gain more knowledge of my } \\
\text { course. }\end{array}$ & & .506 & & & & \\
\hline SE_3 & increase my knowledge of my faith. & & & & $\begin{array}{l}- \\
.801\end{array}$ & & \\
\hline SE_8 & live according to my faith. & & & & $\begin{array}{l}- \\
.756\end{array}$ & & \\
\hline SE_106 & grow in worship and prayer. & $\begin{array}{l}- \\
.509\end{array}$ & & & -687 & & \\
\hline SE_47 & serve God through others. & -526 & & & -668 & & \\
\hline SM_12 & learn the skill how I could handle stress* & & & .795 & & & \\
\hline SM_82 & learn ways to overcome physical fatigue/tiredness. & & & .694 & & & \\
\hline SM_81 & $\begin{array}{l}\text { manage conditions/situations that put me under } \\
\text { stress. }\end{array}$ & & & .652 & & & \\
\hline SM_71 & be aware of my personal qualities or attributes. & & & .651 & & & \\
\hline AI_79 & know how to improve on my weakness. & & & & & .769 & \\
\hline AI_98 & have someone who would listen to me. & & & & $\begin{array}{l}- \\
.510\end{array}$ & .608 & \\
\hline AI_77 & go to places where I could relax or unwind. & & & & .510 & .602 & \\
\hline AI_84 & have a place where there is not much noise. & & & & & .500 & \\
\hline PA_52 & $\begin{array}{l}\text { have the chance of choosing the right course/major } \\
\text { for me. }\end{array}$ & & & & & & -764 \\
\hline PA_29 & have a clear understanding about my own values. & & & & & &. \\
\hline PA_67 & have the trust of my parents. & & & & & & .607 \\
\hline PA_34 & talk to a person whom I can freely express myself. & & & & & & .554 \\
\hline
\end{tabular}

Further, F2 is a factor that contains 6 items linked to career awareness and orientation. Thus, F2 is named as Career exploration. In relation to this, several type of researches point out this particular need among college students, specifically on career indecision, career direction, and career motivation (Simmering \& Wilcox, 1995; Yousefi et al., 2011). And lastly, F1 contains 6 items of family-related needs which are fittingly termed as Family attachment. Similarly, family's influence is superficial and could not be taken away from the students under study (Hannum \& Dvorak, 2004; Garneau et al., 2013).

Confirmatory Factor Analysis:-

Confirmatory factor analysis of the 6-factor model was performed. The steps applied for this analysis involved the model's specification, identification, estimation, assessment, and re-specification which were later performed in the light of Bentler and Wu's (2005) propositions. The most defining moment of drawing out the pattern diagram is to assess how the model fits the data. 
Testing the 6-factor model, the overall need construct reveal that most of the measured variables (dimensions) were strongly correlated with each other except for Family Attachment and Career Exploration (.63), Career Exploration and Self-Management (.86), Family Attachment and Self-Management (.67), Self-Management and Spiritual Enrichment (.62), Career Exploration and Spiritual enrichment (.61), Career Exploration and Personal Autonomy (.61), and Spiritual enrichment and Affective Integration (.67), as shown in Figure 2. This structure coefficient values are considered acceptable correlations when compared to the cutoff point of less than .40 (Hu and Bentler, 1999).

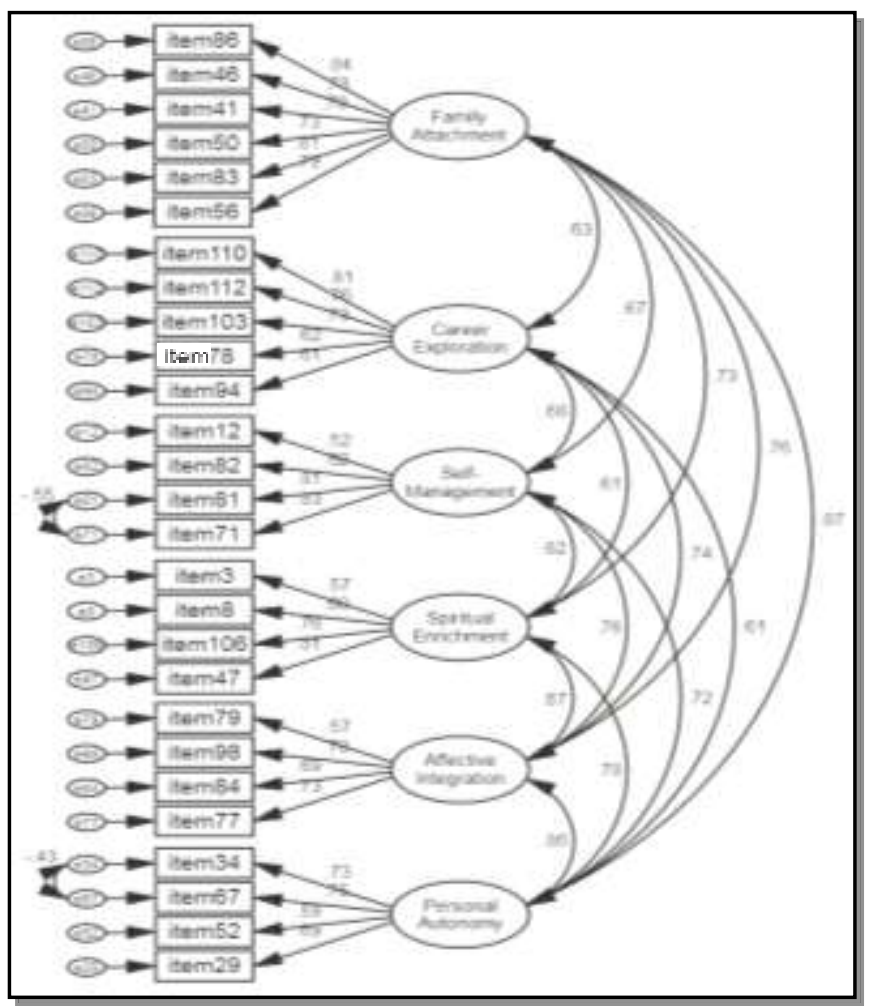

Figure 2:- Structure Coefficients and Correlations of the Six-Factor Higher-Order Model of College Needs

The six-factor multidimensional model of UMNAS contained an overall acceptable fit on the fit indices $\left(\chi^{2}\right.$ df $=$ 540.876; 307; GFI=0.800; AGFI=0.889; TLI=0.874; and RMSEA=0.072). This further revealed the factors identified by EFA are substantially correlated. This also implies that SFSN-C showed a strong theoretical validity to measure the needs of the college students (Elnar, 2018).

\section{Qualitative Analysis of SFSN-C:-}

Using Cohen et al.'s (2013) qualitative item analysis guide, this research found important perceptions that further proved the psychometric quality of the SFSN-C. FGD participants found the test items as non-discriminatory and culture-sensitive regardless of test-takers cultural background, class, disability, and gender differences. They also pointed that the test is reasonable or fair for all test takers despite the presence of those aforementioned characteristics. When they were asked if the test appear to measure it should supposed to measure and were there any items contrary to their expectations, it appeared that their perception was coherent to the ideas of Neukrug and Fawcett (2015) that the test is quite valid to measure what is expected to measure and it can evidently ask (items) the needs of the students and not some other group/population.

Moreover, results of the qualitative analysis revealed that the behavior of the test administrator affect the way they answered the items of the SFSN-C. They perceived that the test administrator's rapport and building of trust prior to the FGD affected their eagerness in answering the needs survey. Moreover, room conditions affected their testtaking performance as many of them were distracted with other students who are inside the testing room and their proximity with other test takers. 
On their perceptions about the test's practicality for use, the number of items of the final version seemed to allow this perception as they considered the test less time to consume. Also, the test takers (FGD participants) considered the instructions clear, concise and easy to understand regardless of intelligence level, adding to the practical capability and validity of the instrument in measuring the needs of the college students.

Finally, the participants suggested that the test should be utilized by all students as the basis for program development of the school. Most of them pointed that the test has a valid and reliable quality, hence it can provide self-awareness/understanding on the current needs of the test takers.

\section{The Utility of the SFSN-C:-}

It was part of the aim of the researcher to examine the usefulness of the standardized instrument since the instrument was developed for diagnostic purposes. Specifically, the instrument was tested on how it could sense possible students' areas of concern in conjunction with other measures (Newton \& Shaw, 2014). This procedure was also incited by the propositions of Baard et al. (1998) that posited that need construct is useful when employed to predict important outcomes such as adjustment, well-being and personality.

Thus, to attain the instrument's utility, the researcher explored the sensibility of the SFSN-C by comparing its results on the responses of the utility sample through the Mooney Problem Checklist (MPC). Aside from conducting an interview with the guidance counselors, the researcher verified the results of the students by comparing the students' results from the SFSN-C and MPC with the students' counseling forms and personal data. Comparing the results of the interview with the guidance counselors and assessment of their personal data and referral forms, the validity scales embedded in the SFSN-C found three outliers from the sample. Having similar results, the qualitative and quantitative responses of the MPC did not coincide, thus it confirmed the capability of the validity scale to screen participants' manipulation of the test.

To further attest the inference of the validity scale on the three outliers, the guidance counselors were interviewed. Based on the result of the interview, students who manifested manipulation of the test have strong tendency to do so since they were among of those students who have behavioral problems referred by their teachers for repeated cheating and were sent to the prefect of discipline for disciplinary actions. As gleaned from the interview with the guidance counselors these students frequented the office for the past 2-3 years and the usual reasons were due to referrals from their subject teachers for showing academic and non-academic issues.

Content Analysis:-

Using a content analysis approach, the subscales of SFSN-C qualitatively correlated with the dimensions of the Mooney Problem Checklist (MPC).

It was gleaned that students' high and low scores in the family attachment items have the positive bearing on their family issues which also reflected their needs in resolving family issues and the like. The same is true with the Career Exploration (CE) and the Future: Vocational and Educational (FVE) dimension of MPC, as well as the relationship of Self-Management (SM) with Social- Psychological Relations (SPR) and Personal- Psychological Relations (PPR) was also established. Lastly, the items of Spiritual Enrichment subscale correlate the moral and spiritual dimension of MPC.

Furthermore, students' areas of concerns were further explored by the researcher using the standard interpretation of SFSN-C wherein it was found that those students who are low in the family attachment subscale of SFSN-C have also shown patterns of issues in their own family as gleaned from their responses on the MPC. They tend to have a low need for family attachments because they wanted to become more independent. Other related concerns were about lying and talking back to their parents wherein most of them reported that they have separated or divorced parents and think that parents sacrifice for them.

For those students who scored average in the family attachment, tends to have worries about a sick family member, parents expectations for them and for not telling parents everything. They also reported an issue about parents who are separated. For students who have scored low in the family attachment, it is revealed that they have issues about parents who sacrifice too much for them and parents who are making too many decisions for them. Not telling parents everything, sickness in the family and the expectations of their parents are also considered issues for them. These findings further revealed that the issues reported by the students tend to have a relationship on their need to 
experience family's love, care, and support. It has also been associated with their needs to get along well their family, able to resolve conflict in the family, and the need to make their family proud of their achievement at school.

The Career Exploration (CE) subscale of SFSN-C was also correlated with MPC's The Future: Vocational and Educational (FVE) dimension. It showed that students who scored average in CE have wanted to have clear career directions and hopes for success in life. They also reported that they have doubts about their chosen field or vocation.

This research also found out the parallel association between self-management (SM) and Social- Psychological Relations (SPR). For instance, students who showed the high need for handling stress, and overcome physical fatigue are likewise showing childishness or immaturity. They likewise exhibit being timid or shy and have concerns about feelings to easily get hurt by others and for the thought of being talked by others. They reported that they tend to avoid someone they don't like. Interestingly, students who are below average in self-management considered feelings of extreme loneliness as one of their personal issues while most of those who fell in the average need reported that they have difficulty in disclosing their issues, too easily led by other people and in speaking or acting without thinking.

On the other hand, a relationship between Self-Management (SM) and Personal-Psychological Relations (PPR) was also established. It was found out that students who showed the high need for handling stress and overcome physical fatigue are afraid of making mistakes, tend to be easily discouraged, have many personal problems, lack of confidence and being lazy.

This research likewise established the relationship between Spiritual Enrichment and Morals and Religion of MPC. It was found out that those students who have the high need for enhancing their spirituality manifested their need to feel closer to God or Supreme Being. They further reported that they have concerns about how to be as honest as they should be, having the certain bad habit, and being troubled by their guilty conscience.

Hence, the differences among those reported issues (family, career, psychological, moral) when categorized by the levels of students' needs, therefore, point to the realization that SFSN-C scores were able to determine the levels of problems or issues experienced by the students. Thus, it further revealed that the instrument could also be used as diagnostic tool to determine plausible issues in the family. However, the researcher acknowledges the limitation of using statistical analysis and must do further research to clarify the linear relationship between the students' needs towards their individual issues.

\section{Conclusion:-}

Aside from the fact that SFSN-C was reliable and valid need instrument, the psychometric utility of SFSN-C was proven useful in diagnosing psychological and personal issues that shown to impact academic achievement (Tinto, 2005), attrition rates (Astin, 1997), and psychological health (Deci \& Ryan, 2012) among college students. It is evident that through the use of this scale, there is a glimpse of better understanding and sound decision outcomes for counselors and clinicians in identifying academic and academic problems which may eventually yield to an effective intervention plan. Further validation is however suggested by comparing results from clinical and non-clinical samples in order to broaden its psychometric soundness and usefulness that cut across samples' characteristics and age groups. 


\section{References:-}

1. Amarnami, R.K., Sta. Maria, M.A., \& Jeswani, S. (2011). Development and validation of relationships outcome measures in positive youth. Presented at the $48^{\text {th }}$ Annual Conference of the Psychological Association of the Philippines, Abstracts of Paper Presented. Iloilo City, Philippines.

2. Astin, A. W. (1984). "Student involvement: A developmental theory for higher education." Journal of College Student Personnel, 25 (2), 297-308.

3. Astin, A. W. (1997). What Matters in College? Four Critical Years Revisited. San Francisco, CA: JosseyBass.

4. Bentler, P. M., \& Wu, E. (2005). EQS for Windows (version 6.1). Encino, CA: Multivariate Software.

5. Burns, M. Vance, D., Szadokierski,I. \& Stockwell, C. (2006). Student Needs Survey: A Psychometrically Sound Measure of the Five Basic Needs. International Journal of Reality Therapy, 25.2 : 4-8.

6. Cohen, R., Swerdlik, M. and Sturman (2013). Psychological Testing and Assessment ( $8^{\text {th }}$ Ed.). USA: McGraw Hill.

7. Crawford, P. (1979). Development of a Student Needs Assessment Inventory for Secondary School Guidance Departments.

8. Creswell, J. W. (2009). Research design: Qualitative, quantitative, and mixed methods approaches (3rd ed.). Thousand Oaks, CA: Sage.

9. Reeve, J., Deci, E. L., \& Ryan, R. M. (2004). Self-determination theory: A dialectical framework for understanding socio-cultural influences on student motivation. Big theories revisited, 4, 31-60.

10. Deci, E. L., \& Ryan, R. M. (2012). Motivation, personality, and development within embedded social contexts: An overview of self-determination theory. The Oxford handbook of human motivation, 85-107.

11. Elnar, R., Almacin, I., Catacutan, A. \& Mondigo, A. (2018). Does Anxiety Fuels Spirituality? A Path Model in the Association between Student's Needs and Global Personality Domains Department of Psychology. International Journal of Social Science and Humanities Research, 6 (2), 454-462. ISSN 2348-3164 (online)

12. Elnar, R. D. B. (2014). Personality traits and occupational interest: Basis for career guidance program.

13. Elnar, R. (2018). The Use of Factor Analyses in Validating Filipino Needs Scale in Tertiary Education. Advances in Social Sciences Research Journal, doi:http://dx.doi.org/10.14738/assrj.55.4549

14. Elnar, R.D. (2015). Development and validation of university of Mindanao needs assessment scale for college students. (Doctoral dissertation, Ateneo de Davao University).

15. Fabrigar, L. R., Wegener, D. T., MacCallum, R. C., \& Strahan, E. J. (1999). Evaluating the use of exploratory factor analysis in psychological research. Psychological methods, 4(3), 272.

16. Feuerborn, L., Chinn, D. (2012). Teacher perceptions of student needs and implications for positive behavior supports. Behavioral Disorders. 37:4, 219-231. Retrieved January 25, 2015, from http://search.proquest.com/docview/1146476563 ?accountid=31259

17. Furr, R.M. and Bacharach, L. (2014). Psychometrics. Singapore: SAGE Publications

18. Giovazolias, T., Leontopoulou, S., \& Triliva, S. (2010). Assessment of Greek University Students' Counselling needs and attitudes: an exploratory study. International Journal for the Advancement of Counselling, 32(2), 101-116.

19. Glasser, W. (1999). Choice theory: A new psychology of personal freedom. HarperPerennial.

20. Harvey, V S., \& Retter, K. (1995). The development of the Basic Needs Survey. Journal of Reality Therapy, 15(1), 76-80.

21. Hu, L. T. \& Bentler, P.M. (1999). Cutoff criteria for fit indexes in covariance structure analysis: Conventional criteria versus new alternatives. Structural Equation Modeling, 6, 1-55.

22. Hyun, J.K., Quinn, B.C., Madon, T., \& Lustig, S. (2006). Graduate student mental health needs: Needs asessment and utilization of counseling services. Journal of College Student Development. 47, 3, 247-266.

23. Kormas, C., Karamali, G., \& Anagnostopoulos, F. (2014). Attachment anxiety, basic psychological needs satisfaction and depressive symptoms in university students: a mediation analysis approach. International Journal of Psychological Studies. ISSN 1918-722X, Vol 6, No 2.

24. Lafond, B. A. G. (2000). Glasser's Reality Therapy approach to relationships: Validation of a Choice Theory Basic Needs Scale (Doctoral Dissertation, St. Mary's University, 2000). Dissertation Abstracts International: section B: The Sciences \& Engineering, 60, 3615.

25. Marshall, D. (2013). The use of Western Standardized Psychological Tests in Non-Western Contexts. Educational Measurement and Evaluation Review , 4:1. Retrieved January 20, 2015, from http://www.ejournals.ph/index.php?journal=EMER\&page=article\&op=view\&path\%5B\%5D=8297. 
26. Mooney, R. L., \& Gordon, L. V. (1950). Mooney Problem Check Lists.[Manual].

27. Neukrug, E \& Fawcett, R.C. (2015). The Essentials of Testing and Assessment: A Practical Guide to Counselors, Social Workers, and Psychologists ( $3^{\text {rd }}$ Ed.). USA: CENGAGE Learning.

28. Newton, P., \& Shaw, S. (2014). Validity in Educational \& Psychological Assessment. USA: SAGE Publications.

29. Picklesimer, B. K., \& Miller, T. K. (1998). Life-Skills Development Inventory-College Form: An Assessment Measure. Journal of College Student Development, 39(1), 100-10.

30. Simmering, M., \& Wilcox, I. B. (1995). Career exploration and identity formation in MBA students. Journal of Education for Business, 70(4), 233-237.

31. Tinto, V. (1987). Leaving College. Chicago: University of Chicago Press.

32. Tinto, V. (2005). Moving from Theory to Action. In. Seidman, A. College Student Retention, Westport, CT: American Council on Education and Praeger Publishers.

33. Vlachopoulos, S. \& Michailidou, S. (2006). Development and initial validation of a measure of autonomy, competence, and relatedness in exercise: The Basic Psychological Needs In Exercise Scale.

34. Yousefi, Z., Abedi, M., Baghban, I., Eatemadi, O., \& Abedi, A. (2011). Personal and situational variables, and career concerns: Predicting career adaptability in young adults. The Spanish journal of psychology, 14(1), 263-271. 